\title{
Atomic-layer-deposited zinc oxide as tunable uncooled infrared microbolometer material
}

\author{
Enes Battal', Sami Bolat ${ }^{1}$, M. Yusuf Tanrikulu ${ }^{*, 3}$, Ali Kemal Okyay², and Tayfun Akin ${ }^{4}$ \\ ${ }^{1}$ Department of Electrical and Electronics Engineering, UNAM - National Nanotechnology Research Center, Bilkent University, \\ Ankara 06800, Turkey \\ ${ }^{2}$ Department of Electrical and Electronics Engineering, Institute of Materials Science and Nanotechnology, UNAM - National \\ Nanotechnology Research Center, Bilkent University, Ankara 06800, Turkey \\ ${ }^{3}$ Department of Electrical-Electronics Engineering, Adana Science and Technology University, Adana 01180, Turkey \\ ${ }^{4}$ Department of Electrical and Electronics Engineering, METU MEMS - Micro Electro Mechanical Systems Center, Middle East Technical \\ University, Ankara 06531, Turkey
}

Received 19 March 2014, revised 30 May 2014, accepted 31 May 2014

Published online 7 July 2014

Keywords atomic layer deposition, bolometers, electrical conduction, semiconductors, thin films, $\mathrm{ZnO}$

*Corresponding author: e-mail mytanrikulu@adanabtu.edu.tr, Phone: +90 32245500 00/2059, Fax: +90 3224550009

$\mathrm{ZnO}$ is an attractive material for both electrical and optical applications due to its wide bandgap of $3.37 \mathrm{eV}$ and tunable electrical properties. Here, we investigate the application potential of atomic-layer-deposited $\mathrm{ZnO}$ in uncooled microbolometers. The temperature coefficient of resistance is observed to be as high as $-10.4 \% \mathrm{~K}^{-1}$ near room temperature with the $\mathrm{ZnO}$ thin film grown at $120^{\circ} \mathrm{C}$. Spectral noise characteristics of thin films grown at various temperatures are also investigated and show that the $120^{\circ} \mathrm{C}$ grown $\mathrm{ZnO}$ has a corner frequency of $2 \mathrm{kHz}$. With its high TCR value and low electrical noise, atomic-layer-deposited (ALD) $\mathrm{ZnO}$ at $120^{\circ} \mathrm{C}$ is shown to possess a great potential to be used as the active layer of uncooled microbolometers. The optical properties of the ALD-grown $\mathrm{ZnO}$ films in the infrared region are demonstrated to be tunable with growth temperature from near transparent to a strong absorber. We also show that ALD-grown $\mathrm{ZnO}$ can outperform commercially standard absorber materials and appears promising as a new structural material for microbolometer-based applications.
1 Introduction $\mathrm{ZnO}$ has found a broad range of applications in thin-film electronics, sensors, and optoelectronics due to its remarkable electronic and optical properties $[1,2]$. Owing to its wide bandgap of $3.37 \mathrm{eV}$ and high defect-related electrical conductivity, $\mathrm{ZnO}$ has long been used as transparent and conducting coatings [3, 4]. The high electron mobility of $\mathrm{ZnO}$, makes it a very suitable material for thin-film transistors in display applications, emerging as a strong rival to amorphous silicon $[5,6]$. $\mathrm{ZnO}$ has also been investigated for ultraviolet sensing applications due to its band edge at $367 \mathrm{~nm}$ [7], however, its infrared properties, especially for imaging applications, have not been exploited.

Microbolometers are the most preferred infrared imagers and have significant advantages compared to cooled detectors such as room-temperature operation, low cost, compactness, high durability, CMOS compatibility, and low weight. In microbolometers, typically, a pixel body consists of an infrared-absorbing layer, a thermally sensitive active layer, and a structural material for mechanical support. The resistance of the active layer changes upon heating of the pixel body by absorbed infrared radiation. The change in pixel resistance is detected via standard CMOS read-out circuitry [8]. Commercial-grade bolometers employ $\mathrm{Si}_{3} \mathrm{~N}_{4}$ as both the structural and the infrared-absorbing layer [8]. The gold standard among thermally sensitive materials are vanadium oxide $\left(\mathrm{VO}_{\mathrm{x}}\right)$ and amorphous silicon $(\mathrm{a}-\mathrm{Si})$, with temperature coefficient of resistance (TCR) values reaching up to -4 and $-2.5 \% \mathrm{~K}^{-1}$, respectively [9-11].

Recently, there is a tremendous effort towards finding alternatives to currently used standard materials in order to push the performance limits of microbolometer devices further. Materials with stronger absorption in the infrared are sought after to increase the responsivity of bolometers [12-14] and/or to reduce the film thicknesses in order to achieve smaller thermal time constants, hence faster 
operation. Materials with higher TCR values can increase the efficiency of the bolometers and provide lower noise equivalent temperature difference (NETD) performance [15-17].

$\mathrm{ZnO}$ has attracted attention to be used as the active layer of the microbolometer detectors, due to its potential to have TCR values higher than that of the commercially used materials. Several research groups have obtained results suggesting that $\mathrm{ZnO}$ indeed has higher TCR values than $\mathrm{VO}_{\mathrm{x}}$ and a-Si [18]. In the reported works, $\mathrm{ZnO}$ films have been deposited using various methods such as pulsed laser deposition (PLD) [18], and sputtering [19]. Zhou et al. used PLD technique for $\mathrm{ZnO}$ deposition, and they observed TCR values ranging from -3.4 to $-13 \% \mathrm{~K}^{-1}$ [18]. However, these values were measured at temperatures much lower than room temperature. Liu et al. have studied the effects of annealing $\mathrm{ZnO} / \mathrm{p}$-Si heterojunctions, on the TCR values of grain boundaries [19]. In their work, they have shown that the annealing of the sputter deposited $\mathrm{ZnO}$ on $\mathrm{p}-\mathrm{Si}$ substrate in a $\mathrm{N}_{2}$ environment at $800{ }^{\circ} \mathrm{C}$ results in positive TCR values, whereas as-deposited layers and the layers annealed in an $\mathrm{O}_{2}$ environment at $800{ }^{\circ} \mathrm{C}$ exhibit negative TCR values. He et al. have observed positive TCR values in the $383-473 \mathrm{~K}$ temperature range with $\mathrm{ZnO}$ nanorods, which have been synthesized using an aqueous solution method [20].

In addition to its potentially high TCR value, the optical properties of $\mathrm{ZnO}$ are also important for simultaneous use as both an infrared-absorbing layer and a thermally sensitive layer in microbolometers. Surprisingly, there are very limited reports on the infrared (IR) properties and applications of $\mathrm{ZnO}$ in the literature. Especially for IR imaging applications, precise knowledge of dielectric optical properties of $\mathrm{ZnO}$ is crucial. In the IR spectrum, free carriers are well known to modulate optical properties in contrast to phonon modes that arise due to crystal structure of materials. Phonon modes of $\mathrm{ZnO}$ thin films grown by the PLD technique have been shown to be very effective in defining the optical constants in the $300-600 \mathrm{~cm}^{-1}(\sim 16-33 \mu \mathrm{m})$ range [21]. However, investigation of IR optical properties of $\mathrm{ZnO}$ thin films grown by the ALD technique, which is known to provide good control over the free-carrier concentration [22], still remains to be explored. Atomiclayer deposition is a promising deposition technique, because of its high uniformity, conformity, and precise control of the thickness of the grown film, even at low temperatures [23]. Up to now, there are no reported works on the use of the ALD-grown $\mathrm{ZnO}$ as IR absorbing or thermally sensitive material for microbolometer applications. In this paper, we investigate, for the first time, the TCR and electrical noise together with the optical properties of ALDgrown $\mathrm{ZnO}$ and discuss its suitability for thermal IR sensing applications. A TCR of $-10.4 \% \mathrm{~K}^{-1}$, which is particularly higher than that of commercially used bolometer materials, has been obtained with $\mathrm{ZnO}$ grown at $120^{\circ} \mathrm{C}$. This material is also shown to have a corner frequency of $2 \mathrm{kHz}$ in the spectral noise power density spectrum. With variation of the growth temperature, the optical properties of the films are shown to vary greatly and an absorbing structure better than a commercially standard material is achieved.

2 Electrical measurements TCR, which represents the normalized change in the resistance with respect to temperature, is calculated by using the following formula:

$$
\mathrm{TCR}=\frac{1}{R} \times \frac{\mathrm{d} R}{\mathrm{~d} T}
$$

where $R$ represents the resistance of the thin film, and $T$ represents the temperature. Figure 1 shows the temperature-dependent resistance and TCR characteristics of the $\mathrm{ZnO}$ thin films grown at $120^{\circ} \mathrm{C}$. The results indicate that the TCR of the grown films strongly depends on measurement
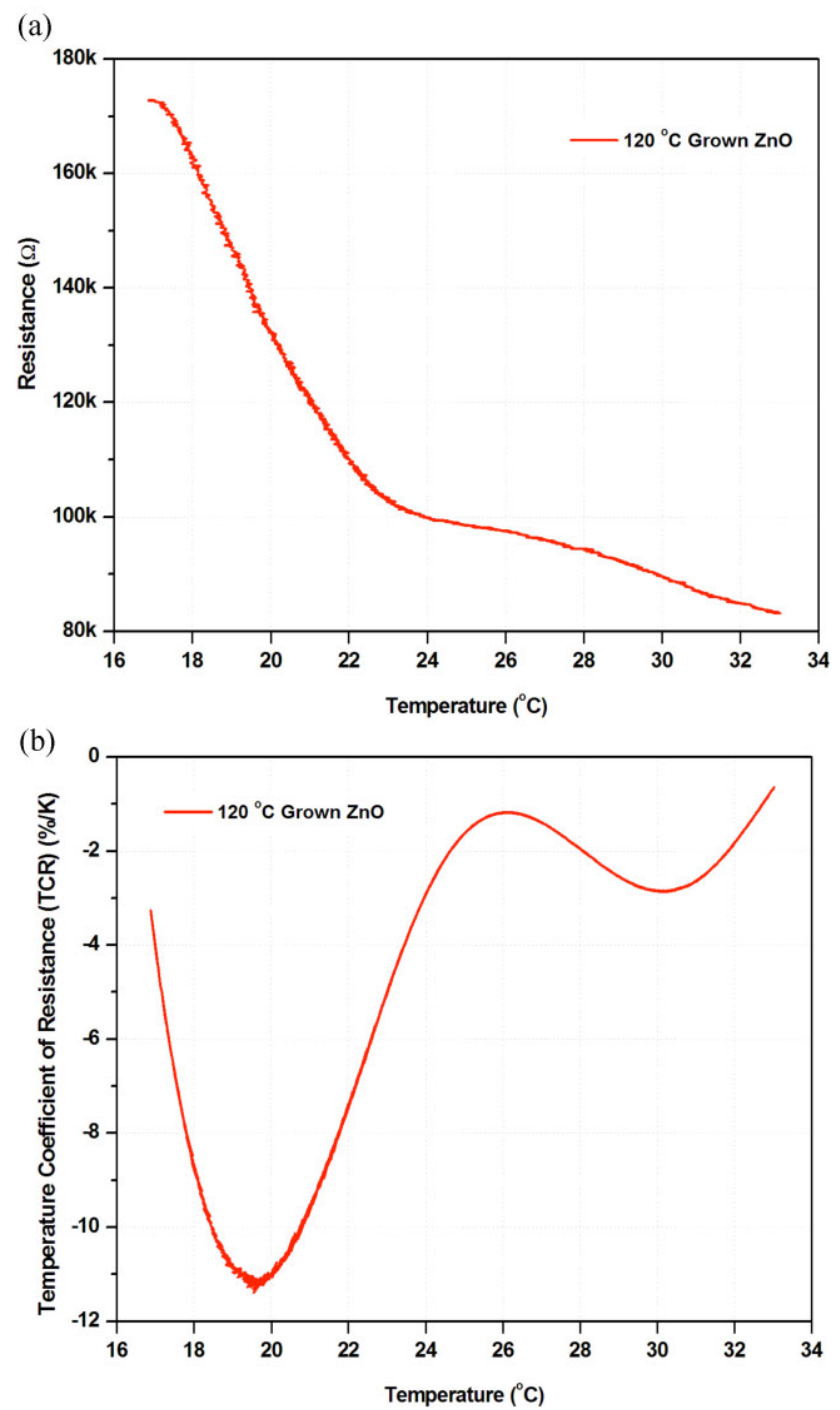

Figure 1 Temperature-dependent resistance and TCR characteristics of $\mathrm{ZnO}$ thin films grown at $120^{\circ} \mathrm{C}$. $\mathrm{ZnO}$ films possess TCR values up to $-10.4 \% \mathrm{~K}^{-1}$ near room temperature, which is higher than the commercial alternatives. Films grown at 200 and $250{ }^{\circ} \mathrm{C}$ exhibit very low TCR $\left(<1 \% \mathrm{~K}^{-1}\right)$ in the measurement range. 
Table 1 Resistivity and maximum TCR values the $\mathrm{ZnO}$ films grown at different temperatures.

\begin{tabular}{llll}
\hline $\begin{array}{l}\text { growth } \\
\text { temperature } \\
\left({ }^{\circ} \mathrm{C}\right)\end{array}$ & $\begin{array}{l}\text { maximum } \\
\text { TCR } \\
\left(\% \mathrm{~K}^{-1}\right)\end{array}$ & $\begin{array}{l}\text { temperature at } \\
\text { which TCR is } \\
\text { maximum }\left({ }^{\circ} \mathrm{C}\right)\end{array}$ & $\begin{array}{l}\text { resistivity } \\
\left(\Omega \mathrm{cm}^{-1}\right)\end{array}$ \\
\hline 120 & -10.4 & 20 & $\begin{array}{l}13.5-100 \\
200\end{array}$ \\
250 & -0.05 & 16 & 0.015 \\
& 0.07 & 16 & 0.009 \\
\hline
\end{tabular}

temperatures and $120{ }^{\circ} \mathrm{C}$ grown $\mathrm{ZnO}$ films possess TCR values up to $-10.4 \% \mathrm{~K}^{-1}$ near room temperature.

For the films grown at 200 and $250{ }^{\circ} \mathrm{C}$, TCR values are near zero, which is generally observed in films with high conductivities. Table 1 shows the maximum TCR of the $\mathrm{ZnO}$ thin films grown at different temperature levels, and the temperature level at which the maximum TCR has been obtained.

The TCR of $\mathrm{ZnO}$ thin film grown at $250{ }^{\circ} \mathrm{C}$ is positive, whereas the TCR values of the films grown at lower temperatures are negative. This suggests that the behavior of a $250{ }^{\circ} \mathrm{C}$ grown film is similar to that of conductors, whereas the $\mathrm{ZnO}$ thin films grown at lower temperatures have the typical behavior of semiconducting materials. This is consistent with the reported resistivity values of ALDgrown $\mathrm{ZnO}$ films in the literature [24].

Table 1 also shows the resistivity of the $\mathrm{ZnO}$ thin films grown at different temperatures. Increasing deposition temperature results in higher free-carrier concentrations, therefore, lower resistivity values. This behavior is in agreement with earlier reports on $\mathrm{ZnO}$ deposited by ALD and sputtering in similar deposition temperature ranges [24]. $\mathrm{ZnO}$ films exhibit n-type behavior, where n-type conductivity is generally attributed to the existence of the zinc interstitials, and oxygen vacancies [25]. The decrease of resistance with increasing deposition temperature indicates that the $\mathrm{ZnO}$ grown at higher temperatures has a $\mathrm{Zn}$-rich composition, whereas the $\mathrm{ZnO}$ films grown at lower temperature levels are oxygen-rich, as previously reported [25]. These results also support the change of sign (from negative to positive) in measured TCR values of $\mathrm{ZnO}$ grown at higher temperatures, suggesting that $\mathrm{ZnO}$ deposited at $250{ }^{\circ} \mathrm{C}$ behaves as a decent conductor, but a semiconductor when deposited at $120^{\circ} \mathrm{C}$.

Active layers with low electrical noise are sought in order to achieve high sensitivity and detectivity in microbolometers. Important components of the electrical noise in microbolometers are mainly flicker noise and thermal noise. The spectral noise analyses of the grown films have been performed on resistors patterned on such films. Figure 2 shows the noise power spectral densities (NPSD) of the thinfilm $\mathrm{ZnO}$ resistors grown at 120,200 , and $250^{\circ} \mathrm{C}$.

A logarithmic NPSD-frequency plot indicates that flicker noise is the dominant mechanism in the 200 and $250{ }^{\circ} \mathrm{C}$ grown $\mathrm{ZnO}$ thin films within the measured frequency range $(0-10 \mathrm{kHz})$. The corner frequency of $120^{\circ} \mathrm{C}$ grown $\mathrm{ZnO}$ is at about $2 \mathrm{kHz}$, which falls in the suitable range for the bolometers operating in snapshot mode [26]. The obtained results suggest that the $\mathrm{ZnO}$ thin film grown at $120^{\circ} \mathrm{C}$ with the ALD method, in terms of electrical properties, is a very promising candidate to be used as the active layer of uncooled microbolometers.

3 Optical measurements Investigation of the optical properties of $\mathrm{ZnO}$ films is crucial for ALD-grown $\mathrm{ZnO}$ to be a candidate for structural or active material for IR microbolometers. The optical properties of the films are described by their complex refractive indices, $\tilde{n}=\sqrt{\varepsilon}=n+j k$, where $\varepsilon$ is the permittivity and $n$ and $k$ are the real and the imaginary parts, respectively. In order to determine the complex refractive indices of the films, a spectroscopic ellipsometry technique is used. In this method, the change in the polarization of the reflected light (a)

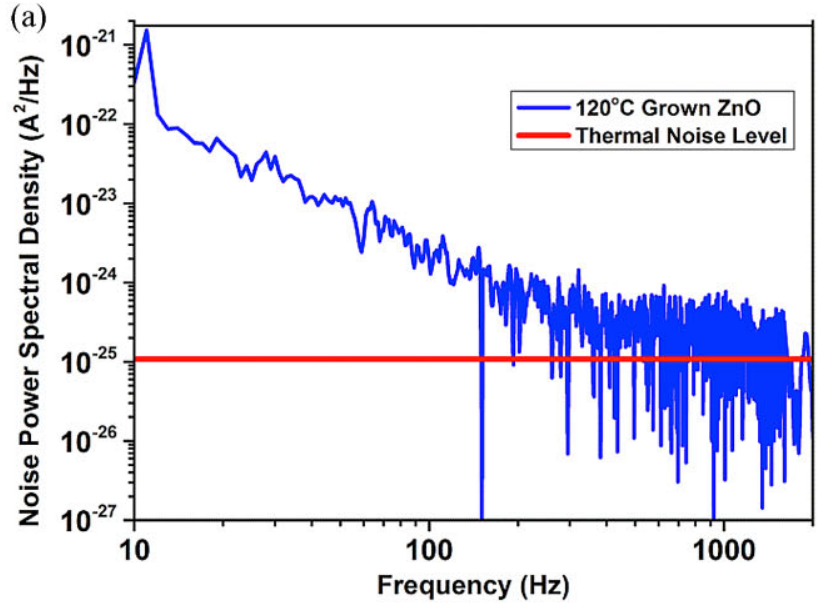

(b)

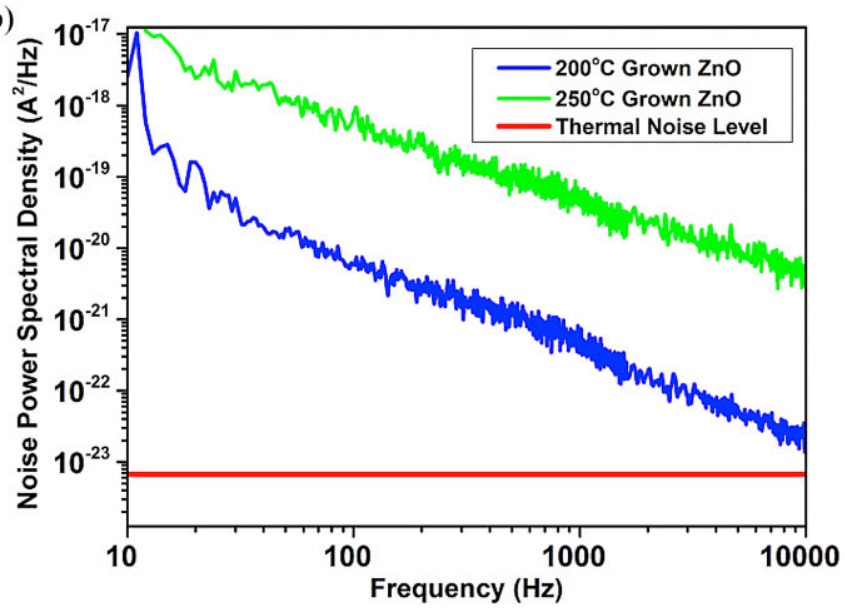

Figure 2 Noise power spectral densities of the thin film $\mathrm{ZnO}$ resistors grown at (a) $120^{\circ} \mathrm{C}$, (b) $200{ }^{\circ} \mathrm{C}$ and $250{ }^{\circ} \mathrm{C}$ show that the $\mathrm{ZnO}$ grown at $120^{\circ} \mathrm{C}$ has a corner frequency of $2 \mathrm{kHz}$, whereas the corner frequencies of the thin films deposited at higher measurements are not observed within the measurement range. 
Table 2 Cauchy dispersion model fit parameters with respect to $\mathrm{ZnO}$ growth temperature for the $400-1700 \mathrm{~nm}$ region where $\mathrm{ZnO}$ films are transparent.

\begin{tabular}{lllllll}
\hline growth temperature $\left({ }^{\circ} \mathrm{C}\right)$ & thickness $(\mathrm{nm})$ & $A$ & $B$ & $C$ & $A_{\mathrm{k}}$ & $E_{\mathrm{k}}(\mathrm{eV})$ \\
\hline 80 & 38.5 & 1.818 & $4.37 \times 10^{-2}$ & $4.13 \times 10^{-4}$ & $4.55 \times 10^{-2}$ & 1.73 \\
120 & 45.5 & 1.816 & $5.05 \times 10^{-2}$ & $3.92 \times 10^{-4}$ & $4.68 \times 10^{-2}$ & 1 \\
200 & 44.9 & 1.813 & $4.74 \times 10^{-2}$ & $2.84 \times 10^{-4}$ & $2.82 \times 10^{-2}$ & 0.2 \\
250 & 34.6 & 1.786 & $3.03 \times 10^{-2}$ & $2.84 \times 10^{-3}$ & $2.18 \times 10^{-2}$ & 0.229 \\
\hline
\end{tabular}

represented by the complex reflectance ratio,

$$
\rho=\frac{r_{\mathrm{p}}}{r_{\mathrm{s}}}=\tan (\Psi) e^{j \Delta}
$$

is determined by measuring $\Psi$ and $\Delta$ that are amplitude ratio and phase shift. Then, these parameters are converted to the Fresnel reflection coefficients for p-polarized $\left(r_{\mathrm{p}}\right)$ and s-polarized $\left(r_{\mathrm{s}}\right)$ light and fit using dispersive dielectric function models.

$\mathrm{ZnO}$ films exhibit transparency starting from the bandgap of $\mathrm{ZnO}$ and reaching up to near-IR wavelengths. Therefore, the Cauchy dispersion model, which is well known to characterize transparent thin films [27], is used in the 400-1700 $\mathrm{nm}$ region to precisely determine the thickness of the films. Cauchy dispersion parameters are defined with the following formula:

$$
\begin{aligned}
& n(\lambda)=A+\frac{B}{\lambda^{2}}+\frac{C}{\lambda^{4}}, \\
& k(\lambda)=A_{k} e^{E_{k}\left((\hbar c / \lambda) E_{b}\right)},
\end{aligned}
$$

where $A, B, C, A_{\mathrm{k}}$, and $E_{\mathrm{k}}$ are fit parameters for the model and $E_{\mathrm{b}}$ is the band edge, which is assumed to be $3.37 \mathrm{eV}$. Table 2 lists the parameters resulting in the best fit.

In the IR region, the effect of free carriers should be taken into account using the Drude oscillator model as IR spectroscopic ellipsometry provides access to the free carriers and the grown films are measured to have a considerable number of free carriers. In the spectral range of interest, 1.8-15 $\mu \mathrm{m}$, the dielectric permittivities of the films are modeled using a Drude oscillator combined with a Lorentz oscillator with the following formulation,

$$
\begin{aligned}
& \varepsilon(\omega)=\varepsilon^{\prime}(\omega)+j \varepsilon^{\prime \prime}(\omega)=\varepsilon_{\infty}+\varepsilon_{\text {Drude }}(\omega)+\varepsilon_{\text {Lorentz }}(\omega), \\
& \varepsilon_{\text {Drude }}(\omega)=-A \frac{\Gamma}{\left((\hbar \omega)^{2}+j \Gamma \hbar \omega\right)}
\end{aligned}
$$

$$
\varepsilon_{\text {Lorentz }}(\omega)=A \frac{\Gamma \hbar \omega_{\mathrm{n}}}{\left(\hbar \omega_{\mathrm{n}}\right)^{2}-(\hbar \omega)^{2}-j \Gamma \hbar \omega}
$$

where $\hbar$ is Planck's constant, $\varepsilon_{\infty}$ is the static dielectric permittivity, $A$ is the amplitude of the oscillator, $\Gamma$ is the broadening, $\omega_{\mathrm{n}}$ is the center frequency of the oscillator, and $\omega$ is the frequency.

Using the determined thickness values in Table 2 and assuming isotropic films, a nonlinear least square error algorithm is employed to fit IR dielectric functions. As the resistivity of the $80{ }^{\circ} \mathrm{C}$ samples is considerably high, the freecarrier effects were not apparent; therefore, Drude oscillator parameters are not used for this growth temperature. Table 3 shows the parameters resulting in the best fit and Fig. 3 depicts the extracted real and imaginary parts of the permittivity as a function of growth temperature. By varying the growth temperature, the fit parameters show significant change in the Drude oscillator parameters due to modulation of free-carrier properties, whereas Lorentz oscillator model parameters are quite invariant. Such invariance of Lorentz oscillator parameters is attributed to be correlated with phonon mode properties of the films, which are not expected to significantly modulate the spectrum of interest by growthtemperature variations.

For control purposes, reflection measurements from $\mathrm{ZnO}$ films are performed using a bare Si wafer as the reference. Figure 4 compares the measured reflection measurements with from $\mathrm{ZnO}$-coated $\mathrm{Si}$ samples with the simulated reflection values generated using the extracted optical constants. Very good agreement between the measurements and the simulations is obtained.

\begin{tabular}{|c|c|c|c|c|c|c|}
\hline \multirow[t]{2}{*}{ growth temperature $\left({ }^{\circ} \mathrm{C}\right)$} & \multirow[t]{2}{*}{$\varepsilon_{\infty}$} & \multicolumn{3}{|c|}{ Lorentz } & \multicolumn{2}{|l|}{ Drude } \\
\hline & & $A$ & $\Gamma\left(\mathrm{cm}^{-1}\right)$ & $\omega_{\mathrm{n}}\left(\mathrm{cm}^{-1}\right)$ & $A\left(\mathrm{~cm}^{-1}\right)$ & $\Gamma\left(\mathrm{cm}^{-1}\right)$ \\
\hline 80 & 3.70 & 35.7 & 47.07 & 396.5 & - & - \\
\hline 120 & 3.71 & 51.2 & 48.3 & 397.3 & 1694 & 8468 \\
\hline 200 & 3.65 & 51.6 & 52.74 & 397 & 8109 & 2024 \\
\hline 250 & 3.25 & 55.8 & 60.98 & 396.5 & 14886 & 2241 \\
\hline
\end{tabular}

The imaginary part of the permittivity $\left(\varepsilon^{\prime \prime}\right)$ is an indicator of the absorption characteristics of the films. The films get highly absorptive with increasing growth temperature as $\varepsilon^{\prime \prime}$ increases significantly. Since highly absorbing films are

Table 3 Fit parameters for the infrared region as a function of $\mathrm{ZnO}$ growth temperature. 
(a)

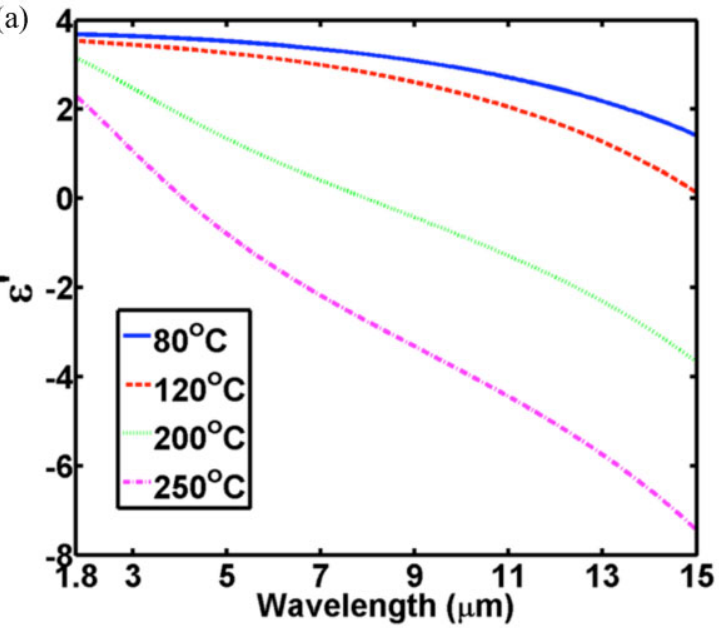

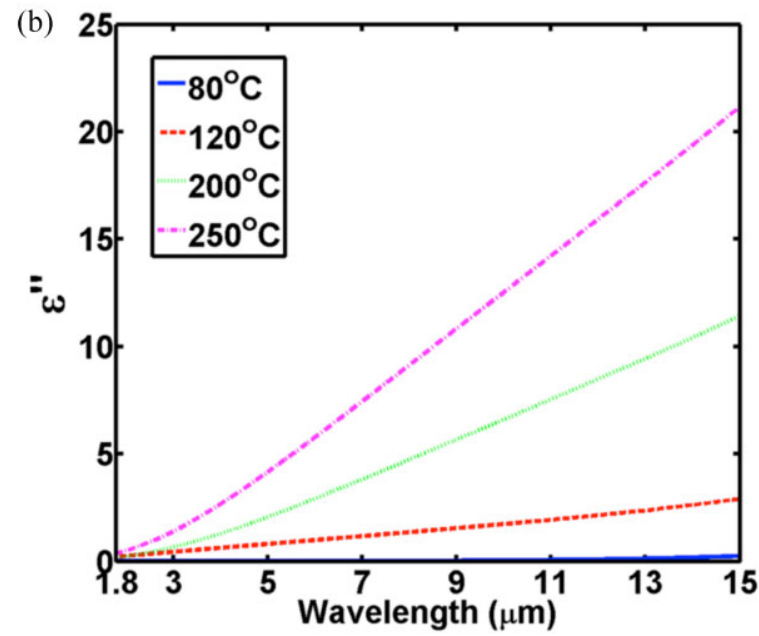

Figure 3 (a) Real $\left(\varepsilon^{\prime}\right)$ and (b) imaginary $\left(\varepsilon^{\prime \prime}\right)$ parts of the permittivities of the grown $\mathrm{ZnO}$ films with respect to growth temperature indicate an increasing metallic behavior with increasing growth temperature, as a result of the rise in the free-carrier concentration.

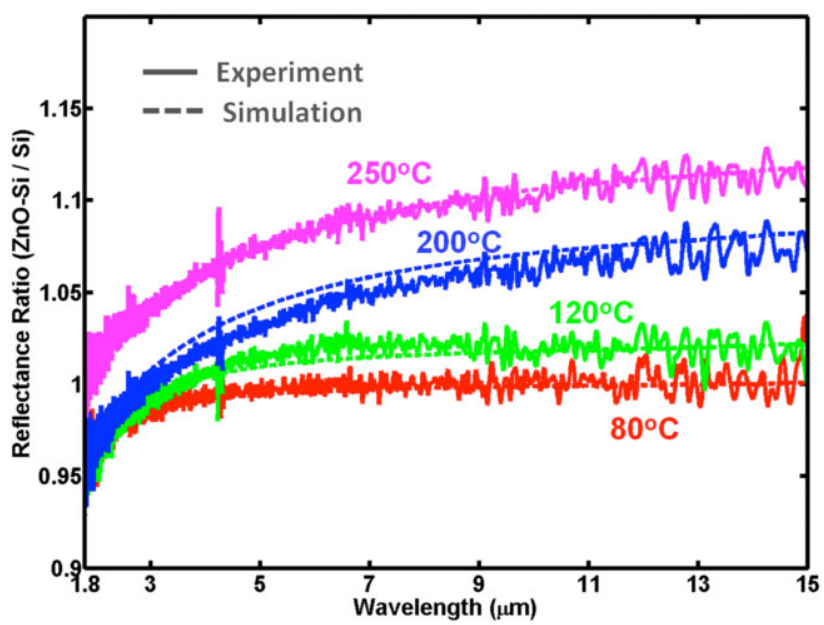

Figure 4 FTIR reflection measurements (solid) and simulations (dashed) using the extracted values yield a very good agreement. Increased reflectance with the increasing growth temperature indicates a better metallic behavior for $\mathrm{ZnO}$ films grown at higher temperatures.

sought after for IR bolometric applications, such high absorption performance and controllability makes ALDgrown $\mathrm{ZnO}$ a potentially very attractive candidate. To exemplify the absorption performance of the films, a theoretical comparison between a reference bolometer structure [28] with a commercially standardized material structural material, $\mathrm{Si}_{3} \mathrm{~N}_{4}$, and the grown films is carried out using FDTD simulations. Figure 5a shows the simulated reference structure, a 400-nm thick suspended absorber layer having an air gap of $2 \mu \mathrm{m}$ above a metallic reflector, using the optical constants of the $\mathrm{ZnO}$ films and $\mathrm{Si}_{3} \mathrm{~N}_{4}$ [28]. Figure $5 \mathrm{~b}$ depicts the simulated absorption spectra of the films. All $\mathrm{ZnO}$ films exhibit a significant amount of absorption in the bolometric region of interest, $8-12 \mu \mathrm{m}$.
In addition, 200 and $250^{\circ} \mathrm{C}$ grown $\mathrm{ZnO}$ films also show considerable amount of absorption in the 3-5 $\mu \mathrm{m}$ region, which is also exploited for bolometric IR imaging purposes. Figure 5c compares integrated absorption in 8-12 $\mu \mathrm{m}$ for $\mathrm{Si}_{3} \mathrm{~N}_{4}$ and the $\mathrm{ZnO}$ films. In this spectrum, all $\mathrm{ZnO}$ films except $80^{\circ} \mathrm{C}$ grown film exhibit absorptivity values comparable to that of $\mathrm{Si}_{3} \mathrm{~N}_{4} \cdot 200^{\circ} \mathrm{C}$ grown $\mathrm{ZnO}$ shows $85 \%$ absorption, which outperforms $\mathrm{Si}_{3} \mathrm{~N}_{4}$ by $13 \%$. Considering the resulting stress-free characteristics along with the remarkable optical performance (see Supporting Information, online at www.pss-a.com), $\mathrm{ZnO}$ films grown at $200{ }^{\circ} \mathrm{C}$ appears as a very attractive structural material for bolometric applications. The relatively lower absorption of $80^{\circ} \mathrm{C}$ grown $\mathrm{ZnO}$ films is attributed to the fact that $\varepsilon^{\prime \prime}$ is well below 1 in the entire spectrum. Yet, this material can still be useful as a low-loss broadband IR antireflective coating layer as its refractive index varies between 1.45 and 1.9.

Modulation of growth temperature also provides control over the real part of the permittivity $\left(\varepsilon^{\prime}\right)$. The wavelength at which the real part of the permittivity equals zero is defined as the plasma wavelength $\left(\lambda_{\mathrm{p}}\right)$ of the material. Above this wavelength, the material exhibits similar optical characteristics to that of a metal due to free carriers. The $\lambda_{\mathrm{p}}$ value of the films redshifts with decreasing growth temperatures, which is an indication of the decreasing carrier conductivity as observed in the electrical measurements. Although 120 and $80^{\circ} \mathrm{C}$ grown samples have a considerable number of free carriers with concentrations on the order of $1 \times 10^{16}$ and $1 \times 10^{17} \mathrm{~cm}^{-3}$, respectively, their $\lambda_{\mathrm{p}}$ do not fall into the region of investigation. However, the trend of the real part of the permittivity indicates that the $\lambda_{\mathrm{p}}$ of $120^{\circ} \mathrm{C}$ is lower than that of $80^{\circ} \mathrm{C}$ due to the higher carrier concentration at $120^{\circ} \mathrm{C}$. For 200 and $250^{\circ} \mathrm{C}$ growth temperatures, $\lambda_{\mathrm{p}}$ is determined to be about 8 and $4.08 \mu \mathrm{m}$, respectively. The increasing reflectivity from the samples with the increasing growth temperature indicates that the highly conductive 
(a)

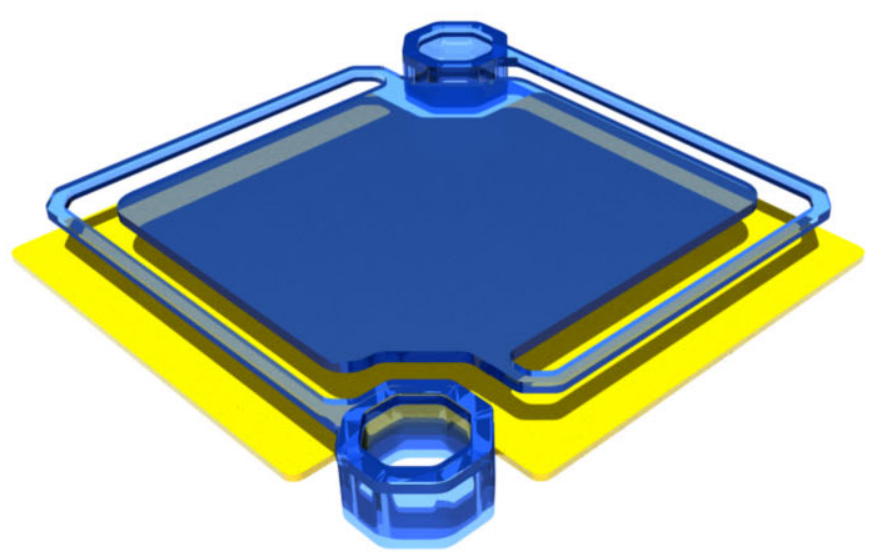

Absorber Reflector (b)

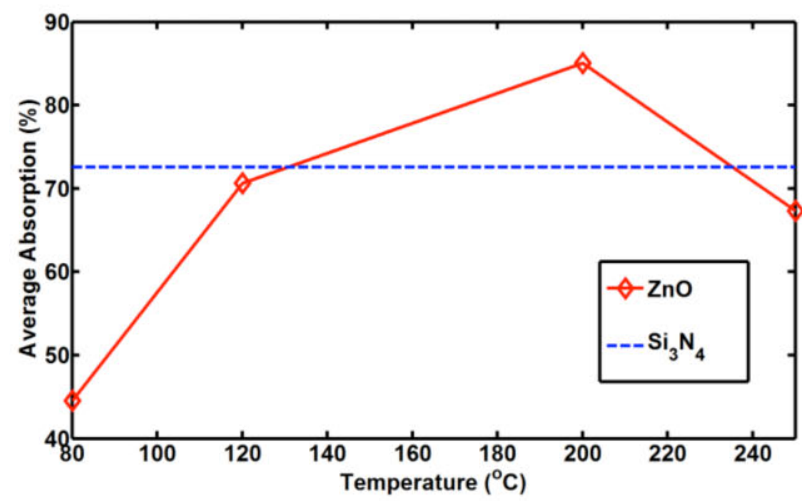

(c)
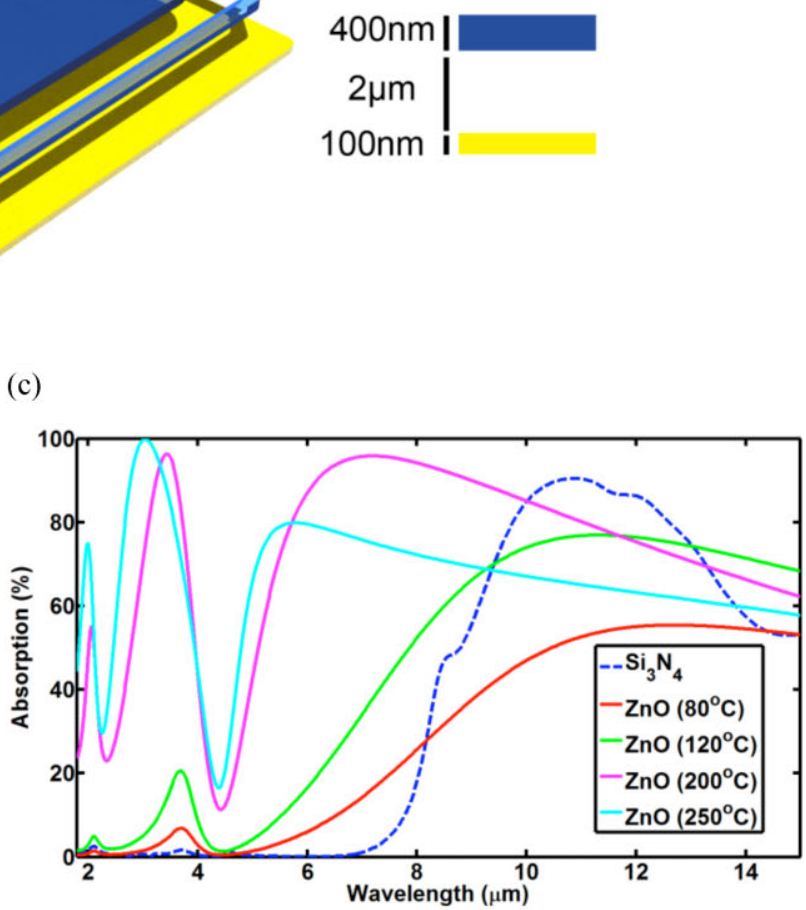

Figure 5 (a) 3D view of the simulated standard bolometer structure. (b) Simulation results of average absorption of $\mathrm{ZnO}$ films in the 8$12 \mu \mathrm{m}$ region indicates a higher performance for $200{ }^{\circ} \mathrm{C}$ grown films compared to $\mathrm{Si}_{3} \mathrm{~N}_{4}$. Broadband absorption characteristics is observed in (c) the absorption spectra of the films including a significant amount of absorption in the 3-5 $\mu \mathrm{m}$ region, as well.

films are closer to the metallic behavior optically. Such metallic behavior sets the scene for exploiting dielectricbased metal-optics in bolometric applications.

4 Conclusion In conclusion, we have investigated the TCR and electrical noise together with the optical properties of the ALD-grown $\mathrm{ZnO}$ for the first time for its usage in uncooled microbolometers. Depositions are performed at various temperatures to observe the effect of the growth temperature on the properties of the $\mathrm{ZnO}$. In terms of electrical properties, a tendency of becoming more conductive with the increase in the deposition temperature has been observed and it is related to the defect-rich structure of the deposited thin film. The optical constants of the films are modeled using the Drude and Lorentz oscillator models. The optical properties of the films can be tailored thanks to the flexibility on controlling the free-carrier concentrations of the films by varying growth temperature in the ALD process. By increasing the growth temperature, the films turn from a poorly absorbing semiconductor to a strongly absorbing highly conductive material. Compared to a standard layer, $200{ }^{\circ} \mathrm{C}$ grown films exhibit greater absorption in a typical bolometer structure. Owing to several advantageous properties obtained by only changing the deposition temperature, ALD-grown $\mathrm{ZnO}$ has a great potential for its usage in uncooled microbolometers. $120^{\circ} \mathrm{C}$ grown $\mathrm{ZnO}$ with the TCR of $-10.4 \% \mathrm{~K}^{-1}$ and flicker noise corner frequency of $2 \mathrm{kHz}$ is a promising candidate on replacing the currently used active layer materials of commercial microbolometers, whereas $200{ }^{\circ} \mathrm{C}$ grown $\mathrm{ZnO}$ with its broad band and high absorption characteristics is a great candidate to replace $\mathrm{Si}_{3} \mathrm{~N}_{4}$ as the structural and absorbing material of uncooled microbolometers.

\section{A Experimental procedure}

A.1 Electrical characterization Electrical characteristics of $\mathrm{ZnO}$ films grown with the ALD technique are investigated. The ALD process is performed in a Cambridge Savannah 100 Thermal ALD system using diethylzinc (DEZ) and milli-Q water $\left(\mathrm{H}_{2} \mathrm{O}\right)$ as reaction precursors. In order to observe the effects of growth temperature, the films are deposited at temperatures of $80,120,200$, and $250{ }^{\circ} \mathrm{C}$. All substrates are cleaned with a standard RCA cleaning process.

Van der Pauw structures are used for resistivity characterization. For flicker noise and TCR measurements, 
(a)

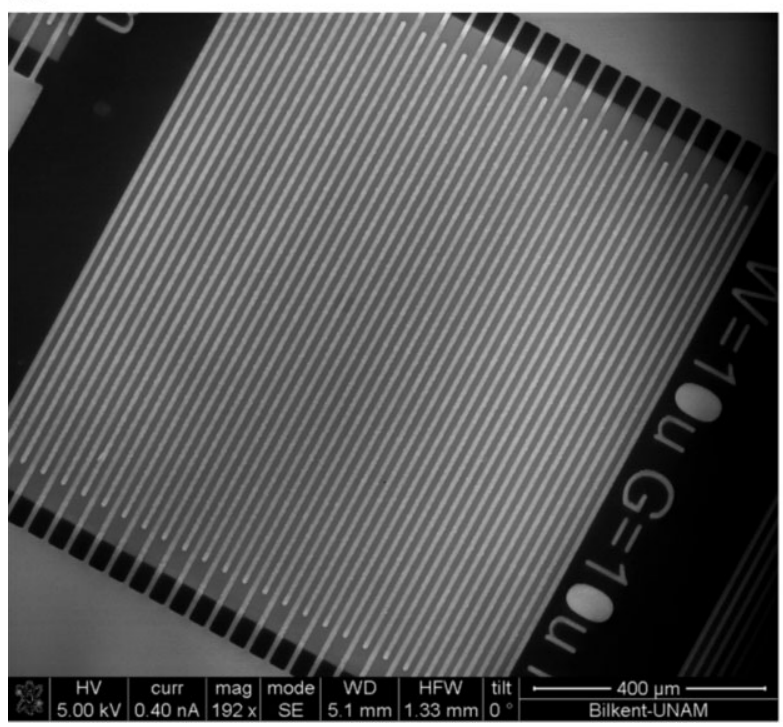

(b)

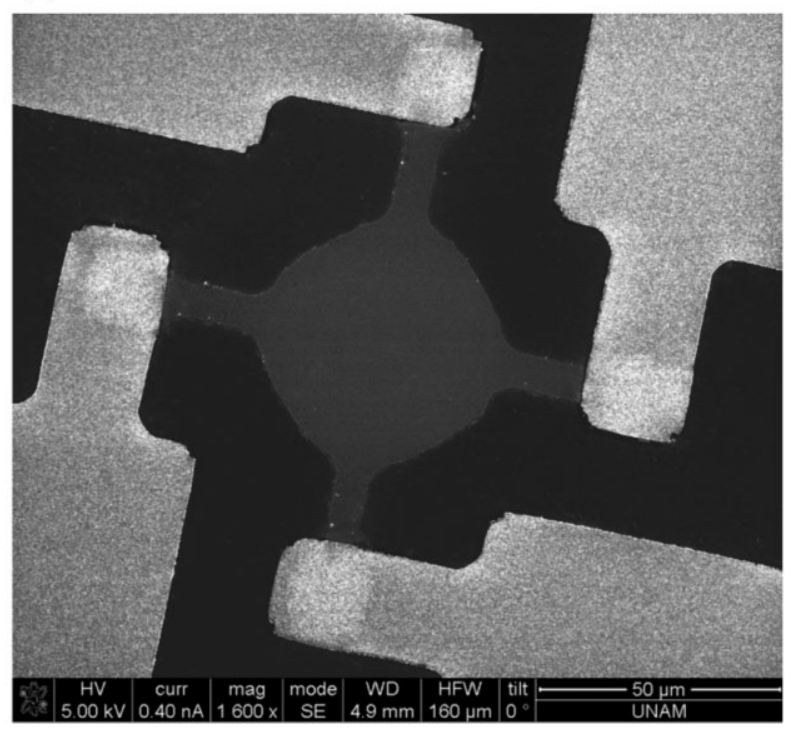

Figure 6 Noise and TCR measurements are carried out with (a) interdigitated finger structures, and resistivity measurements are performed on Van der Pauw structures (b).

interdigitated finger structures are used. Fabrication of structures are performed using standard optical lithography, $\mathrm{BCl}_{3}$-based dry etching of $\mathrm{ZnO}$ and thermal evaporation of metal contacts. SEM images of completed interdigitated and Van der Pauw structures are shown in Fig. 6a and b, respectively. Noise measurements are performed using an analog amplifier integrated with a spectrum analyzer at room temperature. A temperature-controlled environment is used for TCR measurements. The environment temperature is increased from 15 to $35^{\circ} \mathrm{C}$ in a period of $30 \mathrm{~min}$, while voltages across the resistors are recorded under constant current bias.

A.2 Optical characterization Ellipsometric optical characterization is carried out on 300-cycles-thick $\mathrm{ZnO}$ film grown on n-type (100) Si wafers with a resistivity of 3$5 \mathrm{k} \Omega \mathrm{cm}$. For short $(0.4-1.7 \mu \mathrm{m})$ and long $(1.8-15 \mu \mathrm{m})$ wavelengths, commercial spectroscopic ellipsometers, V-Vase and IR-Vase from J.A. Woollam Inc. are used, respectively. The ellipsometric data is collected at incidence angles of both $57^{\circ}$ and $67^{\circ}$ to minimize fit errors. Using a Fourier transform infrared (FTIR) Spectrometer (Bruker Vertex 70 and Hyperion 2000), reflection measurements are performed on the same samples in order to verify the extracted optical properties.

Acknowledgements This work was supported by the Scientific and Technological Research Council of Turkey (TUBITAK), grant numbers 109E044, 112M004, 112E052, 113M815, and 113M912, FP7 Marie Curie IRG grant 239444. A. K. O. acknowledges a Marie Curie International Reintegration Grant (IRG). E. B and S. B. are supported by TUBITAK-BIDEB MS fellowships.

\section{References}

[1] G. D. Yuan, W. J. Zhang, J. S. Jie, X. Fan, J. X. Tang, I. Shafiq, Z. Z. Ye, C. S. Lee, and S. T. Lee, Adv. Mater. 20, 168 (2008).

[2] U. Ozgur, Y. I. Alivov, C. Liu, A. Teke, M. A. Reshchikov, S. Dogan, V. Avrutin, S.-J. Cho, and H. Morkoc, J. Appl. Phys. 98, 041301 (2005).

[3] E. Klaus, J. Phys. D, Appl. Phys. 33, R17 (2000).

[4] A. Yamada, B. Sang, and M. Konagai, Appl. Surf. Sci. 112, 216 (1997).

[5] E. M. C. Fortunato, P. M. C. Barquinha, A. C. M. B. G. Pimentel, A. M. F. Gonçalves, A. J. S. Marques, L. M. N. Pereira, and R. F. P. Martins, Adv. Mater. 17, 590 (2005).

[6] R. L. Hoffman, B. J. Norris, and J. F. Wager, Appl. Phys. Lett. 82, 733 (2003).

[7] Z. K. Tang, G. K. L. Wong, P. Yu, M. Kawasaki, A. Ohtomo, H. Koinuma, and Y. Segawa, Appl. Phys. Lett. 72, 3270 (1998).

[8] A. Rogalski, Infrared Phys. Technol. 43, 187 (2002).

[9] C. Chen, X. Yi, J. Zhang, and X. Zhao, Infrared Phys. Technol. 42, 87 (2001).

[10] E. Mottin, J.-L. Martin, J.-L. Ouvrier-Buffet, M. Vilain, A. Bain, J.-J. Yon, J.-L. Tissot, and J.-P. Chatard, Proc. SPIE 4369, 250 (2001).

[11] Y. Ningyi, L. Jinhua, H. L. W. Chan, and L. Chenglu, Appl. Phys. A 78, 777 (2004).

[12] C. M. Watts, X. Liu, and W. J. Padilla, Adv. Mater. 24, OP98 (2012).

[13] Z. H. Jiang, S. Yun, F. Toor, D. H. Werner, and T. S. Mayer, ACS Nano 5, 4641 (2011).

[14] T. Asano, H. Chong, Z. Yi, L. Mingguo, J. C. Campbell, and A. Madhukar, IEEE J. Quantum Electron. 46, 1484 (2010).

[15] F. B. Atar, A. Yesilyurt, M. C. Onbasli, O. Hanoglu, and A. K. Okyay, IEEE Electron Device Lett. 32, 1567 (2011). 
[16] J. Yan, M. H. Kim, J. A. Elle, A. B. Sushkov, G. S. Jenkins, H. M. Milchberg, M. S. Fuhrer, and H. D. Drew, Nature Nanotechnol. 7, 472 (2012).

[17] A. Y. Glamazda, V. A. Karachevtsev, W. B. Euler, and I. A. Levitsky, Adv. Funct. Mater. 22, 2177 (2012).

[18] X.-F. Zhou, H. Zhang, Y. Li, X.-D. Tang, Q.-M. Chen, and P.-X. Zhang, Chin. Phys. Lett. 27, 018101 (2010).

[19] B. Liu, C. Liu, J. Xu, and B. Yi, J. Semicond. 31, 122001 (2010).

[20] G. He, H. Bo, and S. Hui, Nanotechnology 22, 065304 (2011).

[21] S. Heitsch, C. Bundesmann, G. Wagner, G. Zimmermann, A. Rahm, H. Hochmuth, G. Benndorf, H. Schmidt, M. Schubert, M. Lorenz, and M. Grundmann, Thin Solid Films 496, 234 (2006).

[22] S. J. Lim, S.-J. Kwon, H. Kim, and J.-S. Park, Appl. Phys. Lett. 91, 183517 (2007).

[23] M. Ritala and J. Niinisto, Atomic Layer Deposition, in: Chemical Vapour Deposition: Precursors, Processes and
Applications (The Royal Society of Chemistry, UK, 2009), p. 158, doi: 10.1039/9781847558794-00158.

[24] S. J. Lim, S. Kwon, and H. Kim, Thin Solid Films 516, 1523 (2008).

[25] E. Guziewicz, M. Godlewski, L. Wachnicki, T. A. Krajewski, G. Luka, S. Gieraltowska, R. Jakiela, A. Stonert, W. Lisowski, M. Krawczyk, J. W. Sobczak, and A. Jablonski, Semicond. Sci. Technol. 27, 074011 (2012).

[26] A. Rogalski, Prog. Quantum Electron. 27, 59 (2003).

[27] Y. C. Liu, J. H. Hsieh, and S. K. Tung, Thin Solid Films 510, 32 (2006).

[28] O. Erturk, E. Battal, S. E. Kucuk, A. K. Okyay, and T. Akin, Proc. SPIE 8704, 87041E (2013).

\section{Supporting Information}

Additional Supporting Information may be found in the online version of this article at the publisher's website. 